\title{
Changes in cutaneous microbial abundance with sloughing: possible implications for infection and disease in amphibians
}

\author{
Edward A. Meyer ${ }^{1}$, Rebecca L. Cramp ${ }^{1}$, Manuel Hernando Bernall ${ }^{1,2}$, \\ Craig E. Franklin ${ }^{1, *}$ \\ ${ }^{1}$ School of Biological Sciences, The University of Queensland, St Lucia, Queensland 4072, Australia \\ ${ }^{2}$ Grupo de Herpetología, Eco-Fisiología \& Etología, Departamento de Biología, Universidad del Tolima, Ibagué, Colombia
}

\begin{abstract}
The emergence of disease as a significant global threat to amphibian diversity has generated considerable interest in amphibian defenses against cutaneous microbial infection and disease. To date, however, the influence of sloughing on the susceptibility of amphibians to infection and disease has been largely overlooked. To investigate the potential for sloughing to regulate topical microbial loads, the abundance of cultivable cutaneous bacteria and fungi in the cane toad Rhinella marina were compared before and after sloughing. Toads were also exposed to fluctuating thermal regimes $\left(10-20\right.$ and $\left.20-30^{\circ} \mathrm{C}\right)$ and variable photoperiods to investigate possible effects of season and climate on sloughing periodicity. Sloughing substantially reduced the abundance of cultivable cutaneous bacteria and fungi by up to $100 \%$. The intermoult interval of toads maintained at $10-20^{\circ} \mathrm{C}$ was twice that of animals at $20-30^{\circ} \mathrm{C}$ and did not appear to thermally acclimate. Photoperiod had no discernable influence on sloughing periodicity. Results of this study suggest that normal sloughing cycles could play a significant role in controlling the persistence and build-up of cutaneous microbes, including pathogens. The loss of non-pathogenic commensal and protective skin microbiota after sloughing may also influence host susceptibility to cutaneous pathogens. We suggest that the spatio-temporal dynamics of chytridiomycosis, the widespread and often fatal disease caused by the fungal pathogen Batrachochytrium dendrobatidis, are related to temperature not only because of its effect on the growth of the fungus, but also because of its effect on the frequency of host sloughing.
\end{abstract}

KEY WORDS: Skin $\cdot$ Shedding $\cdot$ Temperature $\cdot$ Rhinella marina $\cdot$ Pathogen $\cdot$ Batrachochytrium dendrobatidis $\cdot$ Commensal microbe $\cdot$ Epidermis $\cdot$ Cutaneous

\section{INTRODUCTION}

The skin of vertebrates serves as a physical barrier to percutaneous intrusion by microbes and consequently plays an important role in defense against pathogenic organisms (see reviews by Proksch et al. 2008, Stockfleth et al. 2009). The outermost layer of the skin, the stratum corneum, is a continuous sheet of stratified keratinocytes that acts as a physical barrier to the intrusion of pathogens as well as reducing evaporative water loss (Proksch et al. 2008). The continuous production and migration of keratinocytes from the basal layers of the epidermis to the surface where they are ultimately sloughed (desquamation) ensures that the barrier function of the skin is maintained at all times. In addition, the process of desquamation itself is an important immune property of the skin as potential pathogens 
and microbes adherent to the most peripheral skin layers can be shed with the shed keratinocytes (Dahl 1993). In amphibians, the stratum corneum is shed on a regular basis (Larsen 1976, Withers 1995); moreover, unlike mammals, sloughing of the stratum corneum in amphibians is usually entire (i.e. all of the stratum corneum is shed at once) (Taylor \& Ewer 1956, Ling 1972, Larsen 1976, Withers 1995). As such, sloughing could play a significant role in regulating the abundance and persistence of microbes, both beneficial and pathogenic, at the body's surface.

To investigate the influence of sloughing on microbial abundances on amphibian skin, we examined changes in the abundance of cultivable cutaneous microbes post-sloughing in cane toads Rhinella marina (Linnaeus, 1758). As ectotherms, physiological processes such as sloughing are likely to be affected by environmental factors such as temperature and day length. Seasonal differences in temperature and photoperiod may, therefore, affect sloughing periodicity and in turn contribute to the seasonality of some amphibian diseases (Berger et al. 2004). To investigate possible effects of season and climate on sloughing periodicity (and the potential efficacy of sloughing in regulating microbial abundances), the influences of environmental temperature and photoperiod on sloughing frequency were also examined.

\section{MATERIALS AND METHODS}

\section{Animal collection and maintenance}

Cane toads Rhinella marina ( $\mathrm{n}=60$ ) were captured from sites around Brisbane (Queensland, Australia) in January 2010. Animals were transported to The University of Queensland and were housed in large crates ( $\mathrm{n}=10$ per crate) containing a thick layer of pine bark chips saturated with water and kept at room temperature $\left(23\right.$ to $\left.25^{\circ} \mathrm{C}\right)$. Toads were marked on the dorsal skin surface between the parotid glands with dots of zinc sunscreen (Le Tan SPF 30+ Zink Sticks) and Stayfast Lipstick (Maybelline Superstay Lipcolor), and marks remained clearly visible as long as animals had not sloughed. Animals were fed daily with crickets and sprayed daily with a water atomiser to maintain a high (>60\%) ambient humidity. Animals were checked twice daily for the loss of lipstick/zinc marking (the loss of marks indicating recent sloughing).

\section{Effects of temperature and photoperiod on sloughing periodicity}

Following sloughing, toads were re-marked and transferred to individual 51 ice-cream containers containing a $2 \mathrm{~cm}$ layer of fresh wet pine bark. Containers ( $\mathrm{n}=20$ per treatment) were placed into one of 3 temperature-controlled cabinets (Percival I-66VLC9, Edwards Instrument Company) set at one of the following temperature and light regimes: (1) $12 \mathrm{~h}$ light:12 $\mathrm{h}$ dark, $20-30^{\circ} \mathrm{C}, \mathrm{n}=20$; (2) $0 \mathrm{~h}$ light:24 h dark, $20-30^{\circ} \mathrm{C}, \mathrm{n}=20$; or (3) $12 \mathrm{~h}$ light:12 h dark, $10-20^{\circ} \mathrm{C}$, originally $\mathrm{n}=20$, however, 4 animals in this group unexpectedly died. All data from animals that subsequently died were excluded from analyses. Temperatures were set to reflect 'natural' diurnal thermal fluctuation patterns with temperatures increasing rapidly from an overnight minimum (occurring at approximately 06:00 h) to a maximum at approximately midday (Fig. 1). Temperatures were recorded continuously using Thermochron iButtons (DS1921G, Alfa-Tek Australia). Animals were fed and provided with fresh water daily, and checked for loss of skin markers, daily. The duration (in days) between marking and loss of marks was recorded as the intermoult interval. Following the loss of marks, animals were immediately remarked. Intermoult intervals were recorded for 4 consecutive moults (3 intermoult intervals) and the mean intermoult interval calculated.

\section{Effect of sloughing on cutaneous bacterial and fungal abundance}

Five days after sloughing and remarking, the skin of 10 random toads from the $20-30^{\circ} \mathrm{C} 12 \mathrm{~h}$ light: $12 \mathrm{~h}$ dark group were swabbed for topical microorganisms in 2 locations (one dorsal and one ventral). Briefly, animals were removed from containers and a sterile cotton tip moistened in sterile ultrapure water (Invitrogen) was rubbed vigourously over $1 \mathrm{~cm}^{2}$ of skin. The tip of the swab was then removed and placed into a sterile $1.5 \mathrm{ml}$ microfuge tube containing $900 \mu \mathrm{l}$ of sterile ultrapure water. Although our study did not discriminate between transient (in flux with the environment, washed off by rinsing), and resident (remaining on skin following rinsing) microbial populations (see Lauer et al. 2008) our swabbing technique would have captured both. The swabbing procedure was repeated on the ventral surface and then the animal was returned to its container. All surfaces, gloved hands and equipment were sterilised 


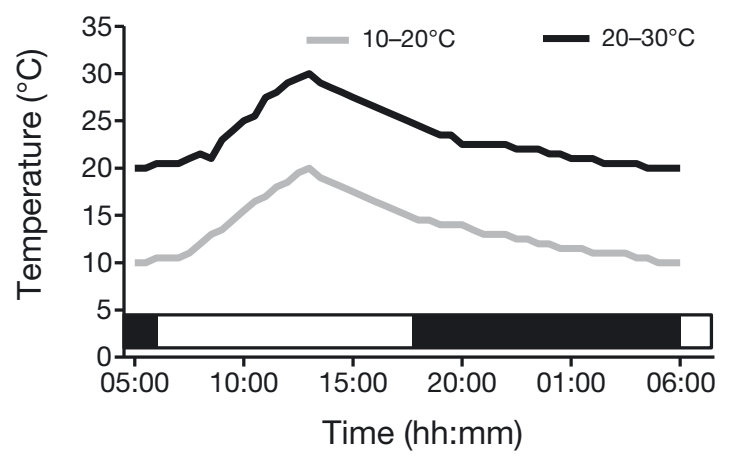

Fig. 1. Rhinella marina. Representative traces from temperature data loggers within $20-30^{\circ} \mathrm{C}$ (black line) and $10-20^{\circ} \mathrm{C}$ (grey line) treatments showing thermal fluctuations over one $24 \mathrm{~h}$ period. Black-and-white bar indicates hours of darkness (black) and light (white) in treatments with a $12 \mathrm{~h}$ light:12 h dark photoperiod

with $70 \%$ ethanol and air-dried prior to and following the handling of each toad to ensure no cross-contamination. Microfuge tubes containing the swab tip and water were vortexed for 30 to $60 \mathrm{~s}$. Samples were then serially diluted in ultrapure water $(10-, 100-$ and 1000 -fold) and a $50 \mu \mathrm{l}$ aliquot from each diluted sample was plated onto nutrient plates optimised for either general aerobic bacterial growth (3M Petrifilm Aerobic Count Plate, Southern Biological) or for general yeast/mould growth (3M Petrifilm Yeast and Mold Count Plate). Plates were divided into 6 so all samples from the same animal (dorsal and ventral) could be plated onto the same plate. Plates were placed individually into clip-seal bags to prevent desiccation and cross-contamination. Bacterial plates were incubated at $36^{\circ} \mathrm{C}$ for $48 \mathrm{~h}$ (Heidolph Unimax 1010, John Morris Scientific) while fungal plates were incubated at room temperature $\left(25 \pm 2^{\circ} \mathrm{C}\right)$ for $4 \mathrm{~d}$. This procedure was repeated for each toad daily, sampling a different dorsal and ventral skin location up to and immediately following sloughing. Three toads sloughed at Day 10, 5 at Day 11, and 2 at Day 12 following the initial slough. Preliminary trials indicated that there was no difference in relative abundance of microorganisms across the dorsal surface and there was no difference in relative abundance of microorganisms across the ventral surface (although there were differences in abundance between the dorsal and ventral surfaces). Control swabs (swabs handled in same manner but without toad contact) were taken and plated frequently throughout the experiment to control for background contamination; however, negligible bacterial and fungal contamination was ever recorded. After incu- bation, plates were scanned with a flat-bed scanner (Cannon CannoScan 8060) and images were analysed with the aid of the program SigmaScan. Petrifilm bacterial plates contained a red indicator dye that coloured colonies red. All red colonies regardless of their size or colour intensity were counted from the diluted sample in which all colonies were clearly visible. Similarly, Petrifilm yeast/mould plates contained an indicator dye to provide contrast and facilitate counting. As with bacterial plates, all colonies regardless of their size or colour intensity were counted from one diluted sample in which all colonies were clearly visible. Colony abundance per $\mathrm{cm}^{2}$ was then estimated for each surface by multiplying colony count by the sample dilution factor.

\section{Statistical analysis}

The abundance of cultivable microbes on the dorsal and ventral skin surface was monitored for up to $5 \mathrm{~d}$ prior to skin sloughing. The changes in microbial abundance in the days prior to sloughing were assessed using linear regression analysis. The percent reduction in microorganism abundance with sloughing was determined by dividing the number of microorganisms recorded on the skin surface on the day of sloughing by that of the day immediately preceding sloughing. Single sample $t$-tests were utilised to determine whether the percent reduction in microorganism abundance was significantly different from zero $(p<0.05)$. The effects of temperature and light regimes on mean intermoult interval were analysed with 1-way ANOVA. Acclimation to thermal conditions occurring over the experimental period was assessed by comparing the length of the first intermoult interval with that of the third intermoult interval with paired $t$-tests. All statistical analyses were conducted using the program GraphPad Prism.

\section{RESULTS}

\section{Effects of temperature and photoperiod on intermoult interval length}

While there was no effect of photoperiod, temperature markedly influenced mean intermoult interval length (ANOVA, $\mathrm{p}<0.001, F=112.6$; Fig. 2A). In animals exposed to a daily fluctuating temperature regime of between 10 and $20^{\circ} \mathrm{C}$, intermoult interval length was almost double that of animals exposed to 

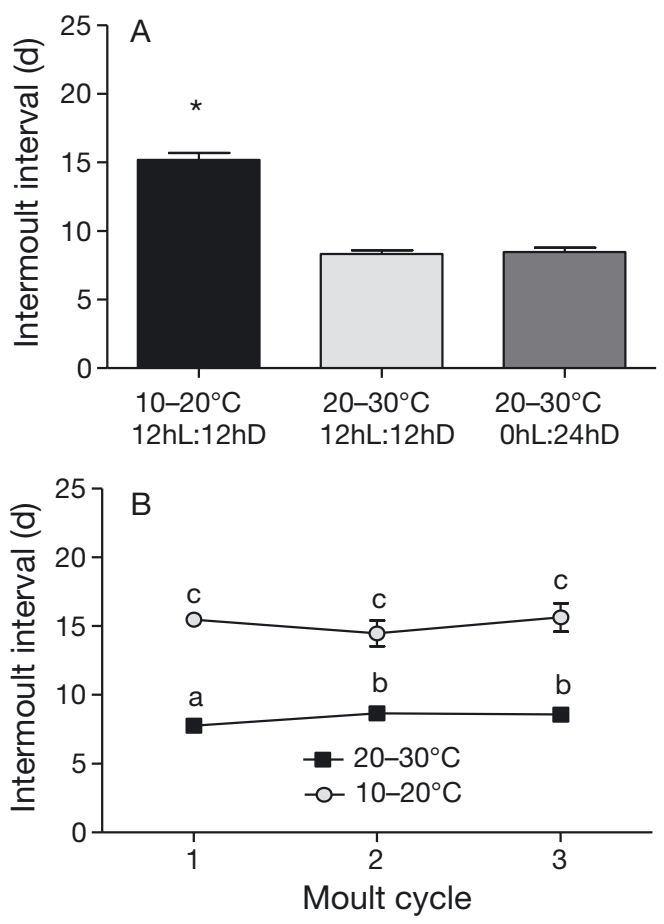

Fig. 2. Rhinella marina. (A) Effects of temperature and day length on mean intermoult interval length (d) in the cane toad. Asterisk indicates treatment group was significantly different from all other groups. Day length had no impact on moult cycle length, while higher mean temperatures significantly reduced intermoult interval. (B) Mean intermoult interval for each of the 3 sloughing cycles in animals chronically exposed to $10-20^{\circ} \mathrm{C}(\mathrm{O} ; \mathrm{n}=16)$ or $20-30^{\circ} \mathrm{C}(\boldsymbol{\square} ; \mathrm{n}=20)$. There was no evidence of thermal acclimation in intermoult interval in animals from cooler temperatures. Data are presented as means \pm SEM. Treatments with the same letter were not significantly different

temperatures that fluctuated between 20 and $30^{\circ} \mathrm{C}$ $(15.2 \pm 0.5 \mathrm{~d}$ versus $8.4 \pm 0.2 \mathrm{~d})$. Although there was a slight but significant increase in mean intermoult interval length over the experimental period in animals from both warm treatments (paired $t$-tests; $0 \mathrm{~h}$ light:24 h dark, $\mathrm{p}=0.005, t=3.156, \mathrm{df}=19 ; 12 \mathrm{~h}$ light: $12 \mathrm{~h}$ dark, $\mathrm{p}=0.03, t=2.238, \mathrm{df}=19$ ), there was no evidence of any thermal compensation occurring in animals exposed to the cold treatment (paired $t$-test, $\mathrm{p}=0.8822, t=0.1507, \mathrm{df}=15$; Fig. 2B).

\section{Effect of sloughing on the abundance of cutaneous microorganisms}

Large numbers of bacteria and fungi were cultured from the dorsal and ventral surfaces. Typically, bacteria were in greater abundance than fungi on all surfaces. Within samples collected from the dorsal surface, microorganism abundance did not vary significantly. Similarly, the ventral surface was also relatively homogeneous with respect to overall microorganism abundance. However, both bacteria and fungi were in greater abundance on the dorsal surface compared with the ventral surface.

In the $5 \mathrm{~d}$ preceding sloughing, the abundance of cultivable bacterial colonies on the dorsal surface increased linearly by more than $300 \%$ (linear regression: $\mathrm{r}^{2}=0.36, \mathrm{p}<0.001$; Fig. 3A). In contrast, bacterial colony abundance on the ventral surface did not change (linear regression: $\mathrm{r}^{2}<0.001 ; \mathrm{p}=0.72$; Fig. 3A), nor did fungal colony abundance change on either skin surface (linear regression: dorsal $\mathrm{r}^{2}=0.1$, $\mathrm{p}=0.46$; ventral $\mathrm{r}^{2}<0.01, \mathrm{p}=0.65$; Fig. 3B) in the days prior to sloughing. On the day before sloughing occurred, the dorsal surface contained the greatest numbers of both bacteria (range: $2.98 \times 10^{5}$ to $1.65 \times$ $10^{6}$ per $\mathrm{cm}^{2} ; \mathrm{n}=10$ ) and fungi (range: $4.19 \times 10^{3}$ to $1.85 \times 10^{4}$ per $\mathrm{cm}^{2} ; \mathrm{n}=10$ ).

Immediately after sloughing, the abundance of cutaneous microorganisms was dramatically reduced
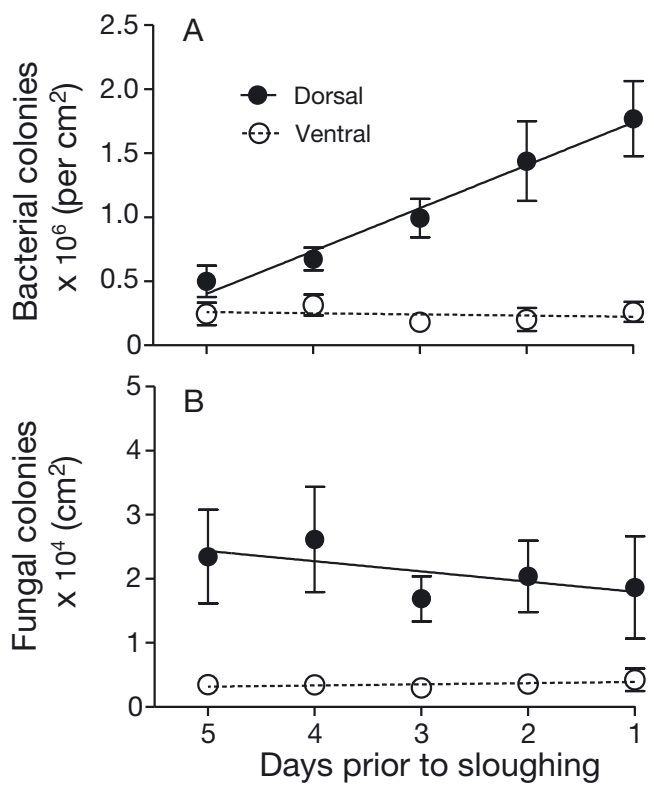

Fig. 3. Rhinella marina. Changes in cultivable (A) bacterial and (B) fungal colony abundance on the dorsal ( $\bullet$ ) and ventral (O) skin surfaces of the cane toad in the days prior to sloughing. Lines represent linear regressions. There was a significant linear increase in bacterial abundance on the dorsal surface in the days leading up to sloughing, but no change over time in bacterial abundance on the ventral surface or fungal abundance on either skin surface. Data are presented as means \pm SEM. Sample size for $5 \mathrm{~d}$ prior to sloughing $=7$; sample size for all other time points $=10$ 


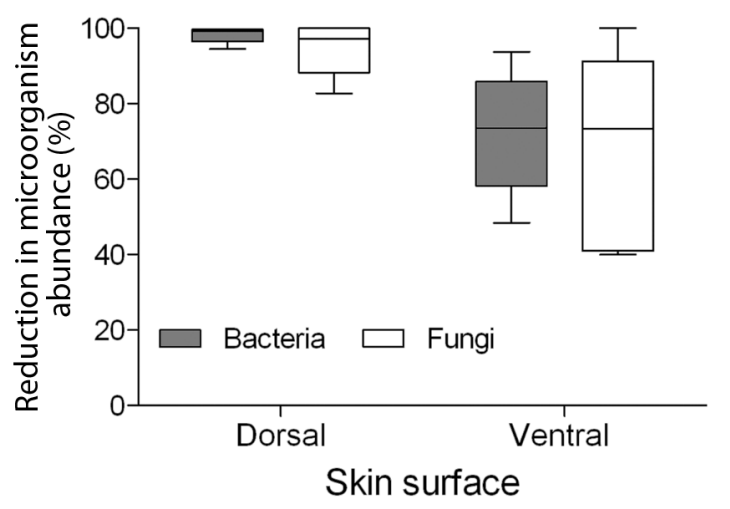

Fig. 4. Rhinella marina. Effects of sloughing on the abundance of skin surface bacteria (shaded boxes) and fungi (open boxes) on the dorsal and the ventral surfaces of the cane toad. Sloughing significantly $(p<0.001)$ reduced the abundance of skin microorganisms on both skin surfaces, in some animals by as much as $100 \%$. The bottom and top lines of the box are the 25th and 75th percentiles, while the middle line represents the median. Whiskers represent minimum and maximum values; $\mathrm{n}=10$

on both the dorsal (bacteria: $97.7 \pm 1.0 \%, \mathrm{p}<0.001$, $\mathrm{n}=10$; fungi: $94.6 \pm 2.2 \%, \mathrm{p}<0.001, \mathrm{n}=10$; Fig. 4) and the ventral body surfaces (bacteria: $71.8 \pm 5.2 \%$, $\mathrm{p}<0.001, \mathrm{n}=10$; fungi: $69.7 \pm 7.9 \%, \mathrm{p}<0.001, \mathrm{n}=10$; Fig. 4). In animals that were in the process of sloughing at the time of swabbing, the reduction in microorganisms with sloughing was $100 \%$.

\section{DISCUSSION}

Regular sloughing of the stratum corneum significantly reduced the abundance of cultivable cutaneous bacteria and fungi and therefore may regulate the build-up and persistence of most microbes, including potential pathogens, present on the outermost skin layers of amphibians. The effectiveness of sloughing in regulating microbial abundance will depend to a large degree on the frequency of sloughing, which, as this and earlier studies (e.g. Taylor \& Ewer 1956) show, is influenced by ambient temperature. Sloughing in Rhinella marina was strongly affected by temperature with the intermoult interval of animals maintained at $10-20^{\circ} \mathrm{C}$ twice that of animals maintained at $20-30^{\circ} \mathrm{C}$. These results are consistent with those of Taylor \& Ewer (1956), who showed that in Bufo regularis maintained at $20^{\circ} \mathrm{C}$, sloughing occurred half as frequently as in animals maintained at $30^{\circ} \mathrm{C}$. Moreover, in B. regularis, sloughing frequency decreased even more dramatically at temperatures below $20^{\circ} \mathrm{C}$, with animals at $15^{\circ} \mathrm{C}$ sloughing 4 times less frequently than animals maintained at $30^{\circ} \mathrm{C}$. Thus, at low temperatures, the efficacy of sloughing as a defense against some pathogenic cutaneous microbes may be markedly reduced and could even increase the susceptibility of frogs to disease.

The intermoult interval in Rhinella marina at $10-20^{\circ} \mathrm{C}$ did not shorten over the experimental period $(6 \mathrm{wk})$, indicating that the acclimation of sloughing frequency (i.e. increased frequency of sloughing with prolonged exposure) at low temperatures is unlikely. This finding is consistent with other studies indicating the capacity of $R$. marina to thermally acclimate to low temperatures is limited (e.g. Kearney et al. 2008). The apparent failure of $R$. marina to acclimate to low temperatures typical of winter in southeast Queensland (where the experimental animals were collected) suggests that sloughing frequency could be significantly affected by seasonal temperature differences, with reduced skin sloughing occurring during cooler times of year. Whether other amphibian species are similarly unable to acclimate sloughing frequency to low temperatures is difficult to say, as data on the effects of prolonged exposure to low temperature on sloughing are limited. Data from Taylor \& Ewer (1956), at least, suggest acclimation of sloughing to low temperatures in Bufo regularis is also unlikely, with no increase in sloughing frequency over time in animals maintained at $20^{\circ} \mathrm{C}$.

Regardless of whether sloughing occurs frequently enough to limit pathogen abundance, the risk of disease will obviously also depend on the thermal biology of the pathogen, specifically the rate at which a microbe grows and multiplies. Microbial growth and reproduction rates are highly temperature-dependent; however, different microbes will have different optimal temperatures for growth and development. As such, the consequences of reduced sloughing frequency at low temperature for disease development will depend on how temperature affects pathogenic microbes. Therefore, a reduction in sloughing frequency at cooler temperatures may have little effect on host susceptibility to diseases caused by pathogenic microbes with higher growth and reproduction rates at warmer temperatures. However, for pathogenic microbes with a higher rate of intrinsic increase at cooler temperatures, reduced sloughing by hosts at lower temperatures would likely facilitate an increase in infection levels and, hence, an increase in host susceptibility to disease.

A reduction in sloughing frequency at low temperatures is of particular concern with regards to 
diseases such as chytridiomycosis, caused by the amphibian chytrid fungus Batrachochytrium dendrobatidis $(B d)$, a novel cutaneous fungal pathogen that flourishes at relatively low temperatures (with high in vitro growth rates occurring at between 7 and $25^{\circ} \mathrm{C}$ depending on the life history stage; Piotrowski et al. 2004, Woodhams et al. 2008). Bd is a significant global threat to amphibian biodiversity, having caused catastrophic population declines and extinctions in many parts of the globe (Skerratt et al. 2007). $B d$ is restricted to the outer keratinized layers of amphibian skin and specifically within cells of the outer layers of the epidermis, the stratum corneum and the stratum granulosum (Berger et al. 2005). Early stages occur in the deeper stratum granulosum and complete their development as the epidermal cells keratinize and mature, and move outwards (Berger et al. 2005). Outbreaks of disease attributed to infection by this fungus often occur in winter and at high altitudes when and where temperatures are low (Berger et al. 2004, Kriger \& Hero 2007, Kriger et al. 2007, Brem \& Lips 2008, Kriger \& Hero 2008, Bustamante et al. 2010). However, at warmer temperatures $\left(>25^{\circ} \mathrm{C}\right)$, fungal growth slows down and sloughing rate increases, and it is possible that the fungus cannot complete its life cycle before being shed. As such, sloughing of this layer could be important in limiting $B d$ infection at high temperature. Indeed, experimentally, $B d$ infections were lost in $50 \%$ of great barred frogs Mixophyes fasciolatus kept at $27^{\circ} \mathrm{C}$ (Berger et al. 2004), although the fungus can survive at this temperature in vitro (Piotrowski et al. 2004). Longer intermoult intervals in amphibian hosts at ambient temperatures below $25^{\circ} \mathrm{C}$ could therefore allow more time for growth and successful reproduction of the pathogen, facilitating an increase in infection levels (Berger et al. 2004). As such, we suggest that the spatio-temporal dynamics of chytridiomycosis are related to temperature not only because of its effect on the growth of $B d$, but also because of its effect on the frequency of host sloughing.

Although in the present study changes in Bd infection levels after sloughing were not measured, evidence from other studies suggests that sloughing of the stratum corneum is likely to reduce $B d$ infection levels in the skin of infected animals (Berger et al. 2005, Becker \& Harris 2010). Several authors have reported an increase in the apparent rate and regularity of sloughing in animals infected with $B d$ (Davidson et al. 2003, Padgett-Flohr 2008), suggesting that increased turnover of epidermal tissues may be one mechanism by which amphibians regulate the build-up and persistence of cutaneous dermatophytes. However, accurate sloughing rates of $B d$ infected frogs have never been empirically examined, so care should be taken with interpretation of incidental findings. In some cases at least, apparent increases in sloughing frequency or irregular sloughing of diseased frogs could be related to inappetence as opposed to increased sloughing periodicity: amphibians clinically infected with $B d$ are typically reluctant to feed (Voyles et al. 2009), which may contrast with healthy, feeding amphibians that regularly eat their slough as it is shed.

Although regular sloughing may help to control the build-up of potentially pathogenic microbes, it is well established that the skin of amphibians also supports a population of commensal microbes that play a vital role in host immunity by suppressing the growth of potentially pathogenic microbes (Belden \& Harris 2007, Lauer et al. 2007, Lauer et al. 2008, Slack et al. 2009, Wiggins et al. 2011, McKenzie et al. 2012). Recent research has suggested that microbiota occurring naturally on the body surface of amphibians may also play an important role in determining host susceptibility to chytridiomycosis, with $B d$ inhibitory bacteria of some species suppressing the growth and reproduction of $B d$ in vitro and in vivo (Woodhams et al. 2007, Harris et al. 2009, Becker \& Harris 2010, Lam et al. 2010). Since most microbiota adhere to the stratum corneum, we hypothesize that sloughing of this layer is likely to affect all adherent organisms (whether parasitic, commensal or mutualistic) in the same way. Frequent sloughing could therefore increase host susceptibility to pathogen invasion and/or establishment unless commensal microbes can rapidly recolonize skin surfaces. Additional research is needed to examine the temporal stability of mutualistic microbial populations on the skin of amphibians over multiple sloughing cycles, particularly in light of the results of our study showing that sloughing can significantly affect the abundance of cultivable microbes on the body surface.

Our study suggests that recolonization of skin surfaces by cutaneous microbes occurs soon after sloughing, with abundances of fungi and bacteria on the ventral body surface plateauing $5 \mathrm{~d}$ prior to sloughing. On the dorsal body surface, however, bacteria continued increasing in abundance up until sloughing. Rapid re-inoculation of skin surfaces by beneficial microbiota following sloughing is integral if competitive inhibition is to be effective in controlling disease-causing pathogens such as $B d$.

The greater abundance of both fungi and bacteria on the dorsal skin surface may reflect differences in 
the topography of skin on the dorsal and ventral body surfaces, with the dorsal surface of Rhinella marina significantly more rugose than the ventral body surface. Swabbing of dorsal skin may therefore have removed microbes from more of the body surface than swabbing of the ventral body, resulting in higher microbial counts from dorsal skin. The placement of pine bark mulch (which has mild antimicrobial properties) at the bottom of containers may also have limited the growth and/or reproduction of microbes on the ventral body surface of cane toads. This could explain why the abundance of cutaneous bacteria on the dorsal body surface was seen to increase continuously and to a much higher abundance over the intermoult period. The influence of substrate on the susceptibility of amphibians to microbial infection has been demonstrated in other studies (e.g. Chambers et al. 2006). Interactions between the environment and the host microbiome may influence host susceptibility to disease in a number of ways. Of particular importance in this regard is the influence of environment on the presence and abundance of beneficial microbes conferring resistance to disease (Belden \& Harris 2007). Given that sloughing in amphibians usually involves the entire epidermis, beneficial microbes must persist in the environment to ensure the rapid re-inoculation of skin surfaces following sloughing. Any disturbance that affects the ability of skin surfaces to rapidly reestablish commensal communities following sloughing may contribute to the emergence of infectious pathogens and associated diseases (see Belden \& Harris 2007 for a review of the importance of environment-host microbiome interactions in disease emergence).

In summary, we stress the importance of skin sloughing in affecting the abundance of skin surface microbes and therefore its potential role as an important first line component of the innate immune system of amphibians. In our study of the cane toad, regular skin sloughing cycles were directly influenced by environmental temperature. Additionally, sloughing periodicity was not affected by prolonged acclimation to low temperatures, which is consistent with other studies showing that the thermal acclimation capacity of tropical amphibians, particularly to low temperatures, is relatively limited (Kearney et al. 2008, Navas et al. 2008). These findings may have major implications for understanding the pathobiology of $B d$, which has devastated amphibian populations globally. Future studies that focus on the potential for sloughing to regulate $B d$ infections are to be encouraged.
Acknowledgements. The authors acknowledge Drs. Lee Skerratt and Lee Berger, who provided valuable comments on an earlier version of this manuscript. Funding for this study was provided by a University of Queensland Research Grant to C.E.F. and an Australian Endeavour Postdoctoral Research Fellowship (ERF_PDR_1210_2009) and El Departamento Administrativo de Ciencia, Tecnología e Innovación de Colombia COLCIENCIAS travel grant to M.H.B. All experiments were carried out with the prior approval of the University of Queensland Animal Welfare Committee (SBS/486/09/URG).

\section{LITERATURE CITED}

Becker MH, Harris RN (2010) Cutaneous bacteria of the redback salamander prevent morbidity associated with a lethal disease. PLoS ONE 5:e10957

Belden LK, Harris RN (2007) Infectious diseases in wildlife: the community ecology context. Front Ecol Environ 5: 533-539

Berger L, Speare R, Hines HB, Marantelli G and others (2004) Effect of season and temperature on mortality in amphibians due to chytridiomycosis. Aust Vet J 82: 434-439

Berger L, Hyatt AD, Speare R, Longcore JE (2005) Life cycle stages of the amphibian chytrid Batrachochytrium dendrobatidis. Dis Aquat Org 68:51-63

Brem FMR, Lips KR (2008) Batrachochytrium dendrobatidis infection patterns among Panamanian amphibian species, habitats and elevations during epizootic and enzootic stages. Dis Aquat Org 81:189-202

> Bustamante HM, Livo LJ, Carey C (2010) Effects of temperature and hydric environment on survival of the Panamanian golden frog infected with a pathogenic chytrid fungus. Integr Zool 5:143-153

> Chambers J, Wilson JC, Williamson IAN (2006) Soil pH influences embryonic survival in Pseudophryne bibronii (Anura: Myobatrachidae). Austral Ecol 31:68-75

Dahl MV (1993) Suppression of immunity and inflammation by products produced by dermatophytes. J Am Acad Dermatol 28:S19-S23

> Davidson EW, Parris M, Collins JP, Longcore JE, Pessier AP, Brunner J (2003) Pathogenicity and transmission of chytridiomycosis in tiger salamanders (Ambystoma tigrinum). Copeia 2003:601-607

Harris RN, Brucker RM, Walke JB, Becker MH and others (2009) Skin microbes on frogs prevent morbidity and mortality caused by a lethal skin fungus. ISME J 3:818-824

- Kearney M, Phillips BL, Tracy CR, Christian KA, Betts G, Porter WP (2008) Modelling species distributions without using species distributions: the cane toad in Australia under current and future climates. Ecography 31: 423-434

Kriger KM, Hero JM (2007) Large-scale seasonal variation in the prevalence and severity of chytridiomycosis. J Zool 271:352-359

> Kriger KM, Hero JM (2008) Altitudinal distribution of chytrid (Batrachochytrium dendrobatidis) infection in subtropical Australian frogs. Austral Ecol 33:1022-1032

> Kriger KM, Pereoglou F, Hero JM (2007) Latitudinal variation in the prevalence and intensity of chytrid (Batrachochytrium dendrobatidis) infection in Eastern Australia. Conserv Biol 21:1280-1290

> Lam BA, Walke JB, Vredenburg VT, Harris RN (2010) Pro- 
portion of individuals with anti-Batrachochytrium dendrobatidis skin bacteria is associated with population persistence in the frog Rana muscosa. Biol Conserv 143: $529-531$

Larsen LO (1976) Physiology of molting. In: Lofts B (ed) Physiology of the Amphibia. Academic Press, New York, NY, p 53-100

Lauer A, Simon MA, Banning JL, Andre E, Duncan K, Harris RN (2007) Common cutaneous bacteria from the eastern red-backed salamander can inhibit pathogenic fungi. Copeia 630-640

Lauer A, Simon MA, Banning JL, Lam BA, Harris RN (2008) Diversity of cutaneous bacteria with antifungal activity isolated from female four-toed salamanders. ISME J 2: $145-157$

Ling JK (1972) Adaptive functions of vertebrate molting cycles. Am Zool 12:77-93

McKenzie VJ, Bowers RM, Fierer N, Knight R, Lauber CL (2012) Co-habiting amphibian species harbor unique skin bacterial communities in wild populations. ISME J 6: 588-596

> Navas CA, Gomes FR, Carvalho JE (2008) Thermal relationships and exercise physiology in anuran amphibians: integration and evolutionary implications. Comp Biochem Physiol A Mol Integr Physiol 151:344-362

Padgett-Flohr GE (2008) Pathogenicity of Batrachochytrium dendrobatidis in two threatened California amphibians: Rana draytonii and Ambystoma californiense. Herpetol Conserv Biol 3:182-191

Piotrowski JS, Annis SL, Longcore JE (2004) Physiology of Batrachochytrium dendrobatidis, a chytrid pathogen of amphibians. Mycologia 96:9-15

Proksch E, Brandner JM, Jensen JM (2008) The skin: an in-

Editorial responsibility: Sven Klimpel,

Frankfurt am Main, Germany dispensable barrier. Exp Dermatol 17:1063-1072

Skerratt LF, Berger L, Speare R, Cashins S and others (2007) Spread of chytridiomycosis has caused the rapid global decline and extinction of frogs. EcoHealth 4:125-134

Slack E, Hapfelmeier S, Stecher B, Velykoredko Y and others (2009) Innate and adaptive immunity cooperate flexibly to maintain host-microbiota mutualism. Science 325 : 617-620

Stockfleth E, Ulrich C, Bos JD, Luiten RM (2009) Skin immune system. In: Stockfleth E, Ulrich C (ed) Skin cancer after organ transplantation, Vol 146. Springer, New York, NY, p 45-62

Taylor S, Ewer DW (1956) Moulting in the Anura: the normal moulting cycle of Bufo regularis Reuss. Proc Zool Soc Lond 127:461-478

Voyles J, Young S, Berger L, Campbell C and others (2009) Pathogenesis of chytridiomycosis, a cause of catastrophic amphibian declines. Science 326:582-585

Wiggins PJ, Smith JM, Harris RN, Minbiole KPC (2011) Gut of red-backed salamanders (Plethodon cinereus) may serve as a reservoir for an antifungal cutaneous bacterium. J Herpetol 45:329-332

- Withers PC (1995) Cocoon formation and structure in the estivating Australian desert frogs, Neobatrachus and Cyclorana. Aust J Zool 43:429-441

Woodhams DC, Vredenburg VT, Simon MA, Billheimer D and others (2007) Symbiotic bacteria contribute to innate immune defenses of the threatened mountain yellowlegged frog, Rana muscosa. Biol Conserv 138:390-398

Woodhams DC, Alford RA, Briggs CJ, Johnson M, RollinsSmith LA (2008) Life-history trade-offs influence disease in changing climates: strategies of an amphibian pathogen. Ecology 89:1627-1639

Submitted: December 5, 2011; Accepted: August 21, 2012 Proofs received from author(s): November 8, 2012 